www.jmscr.igmpublication.org

Impact Factor (SJIF): 6.379

Index Copernicus Value: 71.58

ISSN (e)-2347-176x ISSN (p) 2455-0450

crossref DOI: https://dx.doi.org/10.18535/jmscr/v6i5.133

Journal Of Medical Science And Clinical Research

\title{
Pancreatic Extra Gastrointestinal Stromal Tumor: A Case Report and Review of the Literature
}

\author{
Authors \\ Zubaida Rasool $^{1}$, Suhail Mushtaq Wani ${ }^{2}$, Mubashir ${ }^{3}$, Nuzhat Samoon ${ }^{2}$, Mudasir ${ }^{4}$ \\ Dr Salma Gul ${ }^{5}$ \\ ${ }^{1}$ Associate Professor, MD Pathology, SKIMS, Soura \\ ${ }^{2}$ Senior Resident, MD Pathology, SKIMS, Soura \\ ${ }^{3}$ Associate Professor, MS Surgery, SKIMS, Soura \\ ${ }^{4}$ Senior Resident, MS Surgery, SKIMS, Soura \\ ${ }^{4}$ Post Graduate, Pathology, SKIMS, Soura \\ Corresponding Author \\ Dr Nuzhat Samoon \\ Email: samoon.nuzhat@gmail.com
}

\begin{abstract}
We report a case of 60 years old male who presented with complains of abdominal pain and multiple episodes of vomiting. Endoscopic examination revealed a $2.5 \mathrm{~cm}$ ulcer in second part of duodenum with elevated margins. CECT abdomen revealed a $10 \times 10 \mathrm{~cm}$ lesion in the head of pancreas with perilesional lymphadenopathy. Pylorus preserving pancreaticoduodenectomy was performed. Histopathology and immunohistochemistry examination confirmed the diagnosis of extra intestinal GIST of pancreas with positivity for CD117 and vimentin. This case further proves that this rare tumor can involve pancreas as the primary site. Therefore emphasis should be to include this rare tumor in the differential diagnosis of pancreatic neoplasm.

Keywords: extra gastrointestinal stromal tumor, pancreas, CD117, vimentin, histopathology.
\end{abstract}

\section{Introduction}

The most common malignant condition of pancreas is ductal adenocarcinoma of the exocrine pancreas (about $85 \%$ of all the cases) ${ }^{46,47}$. Whereas primary EGIST of pancreas are extremely rare and constitute only $5 \%$ of GIST $^{37}$, GIST may occur in the entire length of gastrointestinal tract from esophagus to anus, however the most common sites are stomach $(60 \%)$, small intestine $(30 \%)$, rectum $(5 \%)$ and esophagus $(<5 \%)^{37}$. Duodenal GIST constitute
$30 \%$ of all primary duodenal tumors and less than $5 \%$ of GIST $^{38,39,40}$. Sometimes GIST tumor arises from omentum, mesentry, gall bladder, retro peritoneum, but separate from stomach and intestine $\mathrm{s}^{3,7,8,33,42,43}$, in such cases the neoplasm is defined as extra gastrointestinal stromal tumor. EGIST do not display connection to the wall or serosal surface of the viscera. The pancreas is a rare site of origin of EGIST and according to our knowledge only 30cases of EGIST have been reported till date ${ }^{7-31}$. GIST occurs due to the 
neoplastic transformation of interstitial cells of Cajal (ICCS), which normally are the pacemakers of intestinal motility ${ }^{14,52,53}$. EGIST are essentially identical to gastrointestinal counterparts in terms of morphology, molecular profile and IHC. We hereby report a case of pancreatic EGIST and review the literature on pancreatic EGIST.

\section{Case Report}

We report a case of 60 years old male an exsmoker, hypertensive, hypothyroid, from the last sixteen years on medical treatment who presented with complaints of abdominal pain and multiple episodes of vomiting associated with restlessness and giddiness. Physical examination of patient revealed stable general condition. The patient was conscious and oriented. No icterus or cyanosis were present, however, mild pallor was seen. Pulse rate was 78 per minute, B.P 120/60 mm Hg, respiratory rate $16 /$ minute, $\mathrm{Spo}_{2} 94 \%$ off oxygen, temperature 97 degree Fahrenheit. Respiratory system and cardiovascular system examination did not reveal any abnormality. Abdominal examination revealed mild tenderness in epigastrium however abdomen was soft and not distended. Routine investigations revealed: $\mathrm{Hb}-$ $8.8 \mathrm{gm} / \mathrm{dl}$, TLC - 5900/mm3, DLC- neutrophils $65 \%$, lymphocytes $32 \%$, eosinophils $2 \%$, monocytes $1 \%$, Platelets $375,000 / \mathrm{mm} 3$. Urea 42 , creatinine 1.2, bilirubin 0.6, ALT 14, ALP 47, albumin 3.99, Na 138, K 3.6, calcium 8.72. Endoscopy revealed a $2.5 \mathrm{~cm}$ ulcer in D2 with elevated margins. CECT abdomen (figure 1) revealed a $10 \times 10 \mathrm{~cm}$ lesion in the head of pancreaswith perilesional lymphadenopathy. Patient subsequently underwent pylorus preserving pancreaticoduodenectomy (PPPD). Intra operatively a growth measuring $10 \times 10 \mathrm{~cm}$ was seen occupying the periampulary region which appeared to arise from the pancreas (figure 2). Pancreatic duct / common bile duct size was normal. No ascitis was seen. Liver and peritoneum were free. Postoperative period was uneventful and patient was discharged after 15 days.

\section{Macroscopic Examination}

Pancreaticoduodenectomy specimen with duodenum measuring $22 \times 3 \times 3 \mathrm{~cm}$ and pancreas measuring 10x8x8 cm. This lesion was $8 \mathrm{~cm}$ from proximal and $10 \mathrm{~cm}$ from distal duodenal resection margins. On cutting open through duodenum, mucosa was flattened and few ulcerated areas were also seen. While cut section through the pancreas revealed a firm mass in the head of pancreas measuring $8 \times 8 \mathrm{~cm}$, firm in consistency, abutting the ampullary areas of the duodenum. Serial sectioning through the mass revealed grayish white firm area, with focal cystic and hemorrhagic areas, however no areas of necrosis were seen grossly (figure 3 ).

Microscopic examination: sections from the pancreas showed tumor consisting of sheets of spindle cells with intervening fine loose edematous connective tissue. The spindle cells exhibited regular nuclei with fine chromatin, scant to moderate amount of cytoplasm without significant atypia. Mitotic count was $<5 / 50$ HPF (figure 4). At places these spindle cells were arranged in whorled pattern. Few hemorrhagic areas were identified. Sections from the duodenum adjacent to the pancreas and randomly were free of tumor. All the resection margins were free of tumor.

Immunohistochemistry showed strong positivity for CD117(c-kit) (figure 5) and vimentin (figure 6). IHC examination for CD10, PR, CK 8/18,CK 19, pan CK, S-100, synaptophysin and chromogranin were negative. Ki -67 showed $<5 / 50$ hpf mitotic count. Thus a final diagnosis of extra gastrointestinal stromal tumor of pancreas was confirmed. 


\section{JMSCR Vol||06||Issue||05||Page 846-854||May}

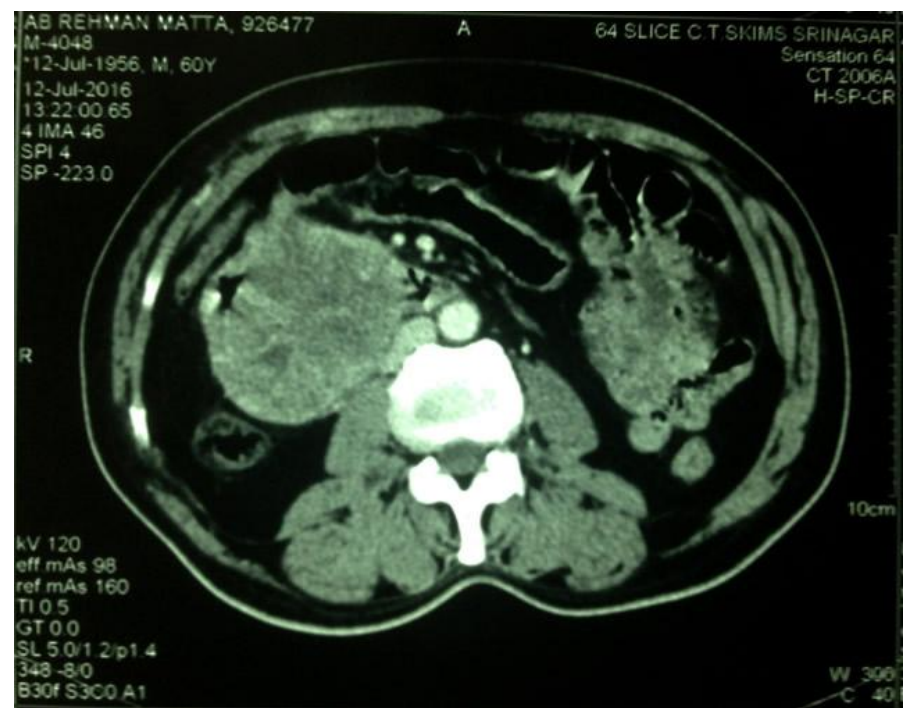

Figure 1 (CECT abdomen)

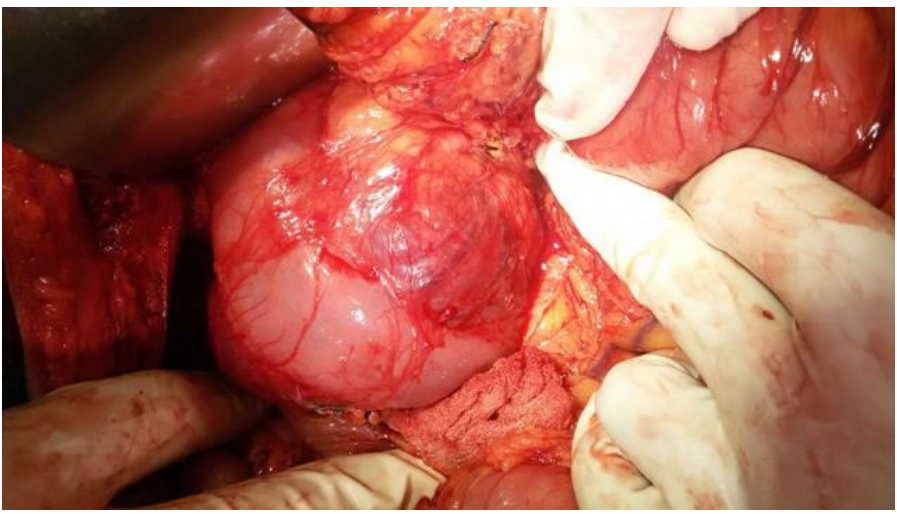

Figure 2 (intra-operative)

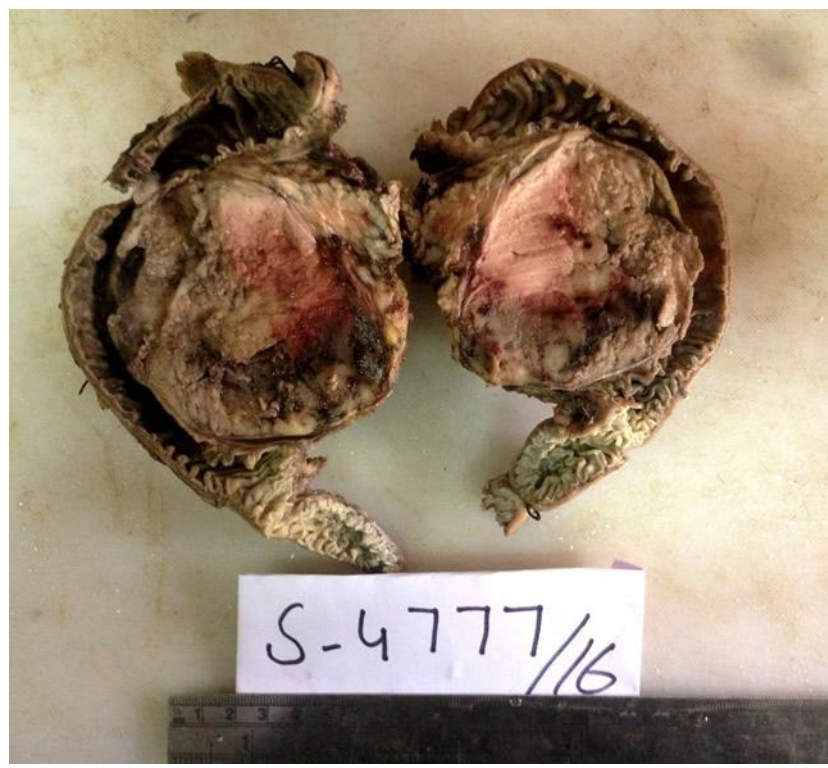

Figure 3 (Gross)

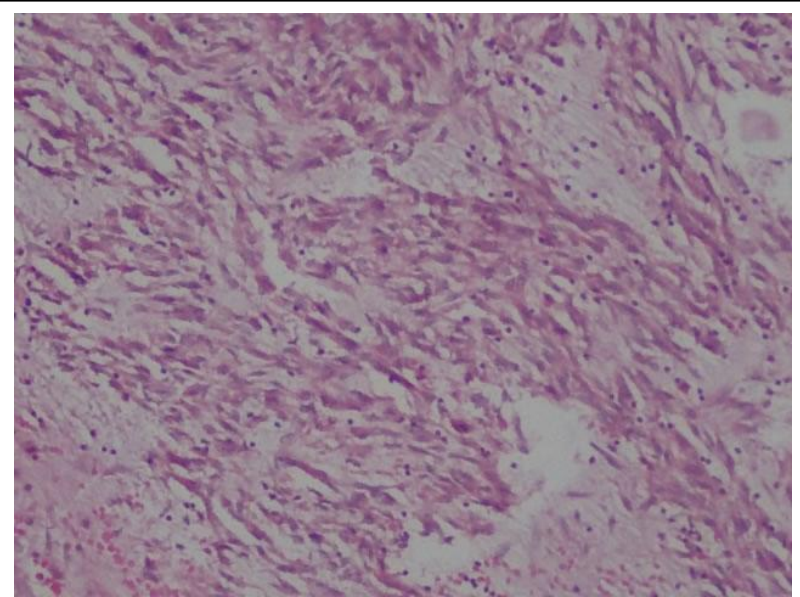

Figure 4 (HPE $40 \mathrm{x}$ )

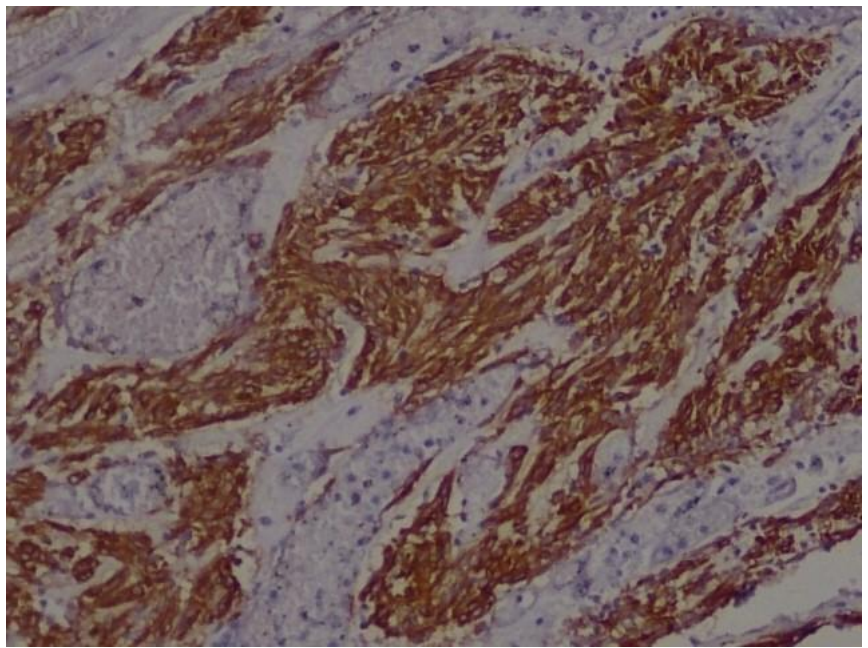

Figure 5 (vimentin)

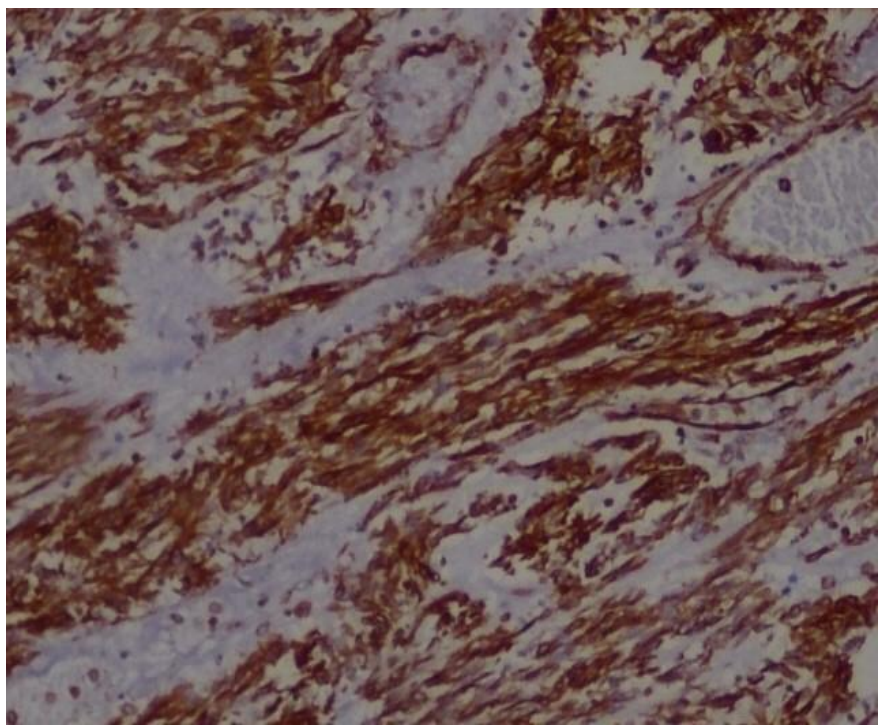

Figure 6 (CD 117)

\section{Discussion}

We report a rare case of primary extra intestinal stromal tumor pancreas. Initial histomorphological examination suggested a differential diagnosis of 
spindle cell neoplasm of pancreas with diagnostic possibilities of

1- spindle cell predominant solid pseudopapillary tumor of pancreas

2- EGIST of pancreas.

However on IHC the final diagnosis of pancreatic EGIST was confirmed which showed strong positivity for CD117 and vimentin.

Cajal was the first to observe interstitial cells of Cajal in intestinal wall in 1982, which were termed "interstitial neural cells". FaussonePellegrini et al ${ }^{5,32}$ viewed the same cells under electron microscope about 80 years later and renamed them interstitial cells of $\mathrm{Cajal}^{5,32}$. Physiological testing has proved that the interstitial cells of Cajal function as the GI pacemakers ${ }^{5,20,32,33}$. Defined by Mazur and Clark in 1983, GIST is the most common non epithelial mesenchymal tumors of the GI $\operatorname{tract}^{5}$.Genetic studies have shown that $90 \%$ cases of GIST have tyrosine kinase gene mutation in c-kit and 5-7\% have mutation in PDGFRA ${ }^{1,5}$. Additional immunomarkers for GIST include DOG 1, and CD117 (a cell adhesion molecule also known as L1) ${ }^{48,49,50,51}$. These markers are expressed independently of kit or PDGFRA status and can therefore be useful for identification of CD117 negative tumors ${ }^{44,45}$. Mesenchymal tumors other than GIST that may stain for CD117 (eg. fibromatosis) tend to show only cytoplasmic positivity with coarse granular pattern. Therefore convincing pattern of CD117 positivity in GIST is one featuring a cell membrane component in addition to the cytoplasmic one. GIST represent $0.1-3 \%$ of all GI tumors and $80 \%$ OF GI mesenchymal tumors. GIST may be present in any site in the GIT where there are interstitial cells of Cajal.

In 2000 Reith et al ${ }^{33}$ first used "EGIST" to define stromal tumors originating from outside the GIT. EGIST represent 5-10\% of all GISTs ${ }^{1,4,5,9,12}$.

In contrast to GISTs, the origin of EGIST is still controversial. It is proposed that these tumors may result from extramural growth of a primary GIST so extensively that they completely lose contact with the muscularispropria of the adjacent structure $^{14,55}$. Alternate suggestions are that both GISTs and EGISTs arise from a common precursor to both the interstitial cells of Cajal (ICCS) and smooth muscle cells. This seems to be more appropriate explanation as the recent studies have confirmed the existence of c-kit positive interstitial cells of Cajal (ICCS) within intestinal organs and vessels. In further support, these cells have also been documented within the exocrine pancreas, further explaining the origin of pancreatic EGISTs ${ }^{8,14,34}$, additionally these pancreatic cells have been shown to respond to imantinib $^{54}$. Studies suggest that EGISTs have a histologically similar presentation to GISTs, but probably behave differently in terms of prognosis and malignant potential. Thus they may require different risk stratification. Furthermore, it has been observed that EGISTs behave similar to GIST in the distal GI tract, in that they are more aggressive with a greater propensity of $\operatorname{metastasis}^{14,23,28,31,41,52,53}$. Some studies have shown highrecurrence rates despite adequate resection and adjuvant therapy ${ }^{12}$.

On the other hand pancreatic EGISTs seem to remain fairly asymptomatic with treatable and favorable survival with low malignant potential. But as there are very few cases available, it is difficult to determine statistically significant trends ${ }^{15,23}$. The severity of symptoms of pancreatic EGIST is related to tumor dimensions and location in pancreas $2,4,7,9,16$. The most common signs and symptoms are abdominal pain, weight loss, fatigue, abdominal mass, abdominal distension, fever, obstruction, GI bleed, anemia, portal vein thrombosis, jaundice, and hepatic encephalopathy ${ }^{4,16,18}$.

The most common diagnostic studies for pancreatic masses include biochemical (carbohydrate antigen 19-9, CEA), radiological, histopathological, immunohistochemical and genetic testing $g^{3,4,5,21}$. However the diagnostic value of tumor markers such as CA 19-9 and CEA for pancreatic EGIST is limited and is rarely used $^{4}$. Abdominal CT, MRI,USG, endoscopic 
USG and PET-CT are the most frequently used radiological techniques in determining tumor localization, dimension, margins, irregularity, invasion of surrounding tissues, distant metastasis and resectibility. However, most of them are non diagnostic. USG and CT are often used in fine needle biopsies ${ }^{5,7,17,20,24,25,28}$. Endoscopic -USG is a valuable diagnostic tool, allowing simultaneous diagnosis and biopsy of solid or cystic pancreatic masses $^{4,5,16,19,20,24}$.

Histopathologically, GISTs are classified into spindle $(70 \%)$, epithelial $(20 \%)$ or mixed $(<10 \%)$ types. Most common variant being spindle cell type $^{4}$. It is therefore, important to differentiate it from other lesions like lieomyoma, leomyosarcoma, liposarcoma, rhabdomyosarcoma, schwanomma, fibromatosis, inflammatory fibroid polyps, solitary fibrous tumor and malignant fibrous histiocytoma ${ }^{3,8,11,24,27}$. Out of the 30 cases of pancreatic EGIST we reviwed, 26 had detailed histopathological data and 25 cases $(96 \%)$ were spindle cell type.

GIST are classified according to their risk of aggressive behavior into

1. very low $(<2 \mathrm{~cm}$ size, $<5 / 50 \mathrm{HPF}$ )

2. low $(2-5 \mathrm{~cm}$ size, $<5 / 50 \mathrm{HPF})$

3 . intermediate $(<5 \mathrm{~cm}$ size, $6-10 \mathrm{HPF}$ or 5$10 \mathrm{~cm}$ size, $<5 / 50 \mathrm{HPF})$

4. High ( $>5 \mathrm{~cm}$ size, $>5 / 50 \mathrm{HPF}$ or $>10 \mathrm{~cm}$ size with any mitotic count $)^{3,4,9,21}$

The risk of aggressive behavior according to these criteria (Fletcher criteria) was determined in 25 cases out of 30 cases in our literature review. Risk of pancreatic EGIST aggressive behavior was high in 17 cases. Out of remaining 8 cases, 7 cases were intermediate risk and one case was low risk.

The most effective treatment option for pancreatic EGISTs is complete resection with microscopically clean margins $(\mathrm{R} 0)^{4,5,36}$, followed by neoadjuvant therapy and debulking surgery for advanced or metastatic disease $e^{2,5}$.Duodenum preserving pancreatic head resection may be performed for small tumors, low grade tumors or patients who cannot tolerate the Whipples procedure $^{4,36}$. Standard pylorus preserving pancreaticoduodenectomy is the optimal treatment for pancreatic head tumors ${ }^{4}$. Radical surgical treatment may be the best option for preventing loco-regional or distant metastases ${ }^{13,15}$. Routine and regional lymph node dissection is not indicated in pancreatic EGIST as nodal metastasis is rare r, $^{4,16,18}$.

In our patient, pylorus preserving pancreaticoduodenectomy was performed. No adjuvant therapy was given as the tumor showed low mitotic activity and no necrosis or metastasis was seen either. Complete resection and clean margins were obtained.

The response of GIST to conventional chemotherapy and radiotherapy were very limited, being $10 \%$ and $5 \%$ respectively ${ }^{9,21}$. However with the induction of imatinibmesylate, a tyrosine kinase inhibitor, the response rates changed quite dramatically. The positive response to imatinib in patients with GISTs is $60-70 \%{ }^{4}$. Recently new tyrosine kinase inhibitors such as sunitinib, nilotinib, sorafenib, divitinib and dasatinib were introduced $^{2,5,23}$. Imatinib may be used as a neoadjuvant agent to downstage gross tumor volume for $\mathrm{R} 0$ resection and contributes to good prognosis ${ }^{4}$. Imatinib can also be used as adjuvant treatment in cases with R1 (microscopic positive margin) or R2 (residual gross visible tumor) resection, risk of aggressive behavior or poor prognostic features 4,5 . Similarly imatinib treatment may be used as a primary modality in metastatic or unresectable cases to reduce tumor size, resulting in better prognosis ${ }^{4}$.

Out of the thirty cases we reviewed from the literature the age of patients ranged from 30 years to 84 years, with mean age of 62 years. Male and female ratio was 1:1. Most common location of the tumor was head of pancreas followed by tail and the least common site was the uncinate process. The most common clinical presentation was abdominal pain which was presenting symptom in ten cases followed by abdominal discomfort (3 cases) and fatigue (3 cases); however it was an incidental finding in 7 cases. Most frequently used radiological investigation 
was CT scan followed by USG and MR. The most frequent surgical procedure performed was distal pancreatectomy with splenectomy followed by whipple procedure. Most common cell type was spindle cell type EGIST (25 cases), with high risk cases being the most frequent (17 cases) followed by intermediate risk ( 7 cases) and low risk (1 case) whereas, in 5 cases no information about the mitotic count was provided. On IHC examination all the cases were positive for CD117 and CD34 was positive in 21 cases. Recurrence after surgery was noted in 6 cases (12 months -24 months), no recurrence was noted in 15 cases, whereas in 6 cases no information was available and in 3 cases surgery was not performed. Death was reported in 2 cases, in 2 cases no follow up information was available, remaining 26 cases were alive in the follow up period ranging from 1 month to 58 months. Medical treatment with gleevec was given in 13 cases, no information was available in 9 cases whereas, 8 cases did not receive any post surgical chemotherapy ${ }^{1-4,7-21,23-25,27-31}$.

In conclusion EGIST is a recently introduced concept and because of the limited cases and studies on EGIST including pancreatic EGIST, limited our evidence based study. Long term follow up studies are needed to further enhance our knowledge about the behavior, prognosis and treatment response of EGIST and to know the differences and similarities of GIST and EGIST.

\section{References}

1. Serin KR, Keskin M, Gulluoglu M, Emre A. Atypical localisation of a gastrointestinal stromal tumor: A case report of pancreas gastrointestinal stromal tumor. Ulusal Cer Derg. 2013;29:42-44.

2. Wegge J, Bartholomew DM, Burke LH, Miller LA. Pancreatic extra-gastrointestinal stromal tumour masquerading as a bleeding duodenal mass. BMJ Case Rep. 2012;2012

3. Kim HH, Koh YS, Park EK, Seoung JS, Hur YH, Kim JC, Cho CK, Kim HJ. Primary extragastrointestinal stromal tumor arising in the pancreas: report of a case. Surg Today. 2012;42:386-390

4. Tian YT, Liu H, Shi SS, Xie YB, Xu Q, Zhang JW, Zhao DB, Wang CF, Chen YT. Malignant extra-gastrointestinal stromal tumor of the pancreas: report of two cases and review of the literature. World $\mathbf{J}$ Gastroenterol. 2014;20:863-868.

5. Padhi S, Sarangi R, Mallick S. Pancreatic extragastrointestinal stromal tumors, interstitial Cajal like cells, and telocytes. JOP. 2013;14:1-14.

6. Miettinen M, Sobin LH, Sarlomo-Rikala M. Immunohistochemical spectrum of GISTs at different sites and their differential diagnosis with a reference to CD117 (KIT) Mod Pathol. 2000;13:11341142.

7. Rao RN, Vij M, Singla N, Kumar A. Malignant pancreatic extra-gastrointestinal stromal tumor diagnosed by ultrasound guided fine needle aspiration cytology. A case report with a review of the literature. JOP.2011;12:283-286.

8. Padhi S, Kongara R, Uppin SG, Uppin MS, Prayaga AK, Challa S, Nagari B, Regulagadda SA. Extragastrointestinal stromal tumor arising in the pancreas: a case report with a review of the literature. JOP.2010;11:244-248.

9. Čečka F, Jon B, Ferko A, Šubrt Z, Nikolov DH, Tyčová V. Long-term survival of a patient after resection of a gastrointestinal stromal tumor arising from the pancreas. Hepatobiliary Pancreat Dis Int. 2011;10:330-332.

10. Goh BK, Chow PK, Kesavan SM, Yap WM, Chung YF, Wong WK. A singleinstitution experience with eight CD117positive primary extragastrointestinal stromal tumors: critical appraisal and a comparison with their gastrointestinal counterparts. J Gastrointest Surg. 2009;13:1094-1098. 
11. Paklina OV, Setdikova GR, Voskanyan SE. Extragastrointestinal stromal tumor of the pancreas: A case report. 25 th European congress of pathology Lisbon. Poster No: 14; 2013.

12. Barros A, Linhares E, Valadão $M$, Gonçalves R, Vilhena B, Gil C, Ramos C. Extragastrointestinal stromal tumors (EGIST): a series of case reports. Hepatogastroenterology. 2011;58:865868.

13. Babu SR, Kumari S, Zhang Y, Su A, Wang W, Tian B. Extra gastrointestinal stromal tumor arising in the pancreas: a case report and literature review. J GHR. 2012;1:80-83.

14. Vij M, Agrawal V, Pandey R. Malignant extra-gastrointestinal stromal tumor of the pancreas. A case report and review of literature. JOP. 2011;12:200-204.

15. Yang $\mathrm{F}$, Jin $\mathrm{C}$, Fu D, Ni Q. Extragastrointestinal stromal tumor of the pancreas: clinical characteristics, diagnosis, treatment, and outcome. J Surg Oncol. 2011;103:739-740.

16. Soufi M, Bouziane M, Massrouri R, Chad B. Pancreatic GIST with pancreas divisum: A new entity. Int J Surg Case Rep. 2013;4:68-71.

17. Joshi J, Rustagi T. Pancreatic ExtraGastrointestinal Stromal Tumor: An Unusual Presentation of a Rare Diagnosis. Gastrointest Cancer Res. 2010;(Suppl 1):S29-S30.

18. Crisan A, Nicoara E, Cucui V, Cornea G, Laza R. Prolonged fever associated with gastrointestinal stromal tumor-case report. J Exp Med Surg Res. 2010;17:219224.

19. Saif MW, Hotchkiss S, Kaley K. Gastrointestinal stromal tumors of the pancreas. JOP. 2010;11:405-406; author reply 412.

20. Harindhanavudhi T, Tanawuttiwat T, Pyle J, Silva R. Extra-gastrointestinal stromal tumor presenting as hemorrhagic pancreatic cyst diagnosed by EUSFNA. JOP. 2009;10:189-191.

21. Trabelsi A, Yacoub-Abid LB, Mtimet A, Abdelkrim SB, Hammedi F, Ali AB, Mokni M. Gastrointestinal stromal tumor of the pancreas: A case report and review of the literature. $\mathrm{N}$ Am $\mathrm{J}$ Med Sci. 2009;1:324-326.

22. Yang F, Long J, Di Y, Fu DL, Jin C, Ni QX, Zhu HG. A giant cystic lesion in the epigastric region. Pancreatic malignant gastrointestinal stromal tumour (GIST) Gut. 2008;57:1494, 1636.

23. Showalter SL, Lloyd JM, Glassman DT, Berger AC. Extra-gastrointestinal stromal tumor of the pancreas: case report and a review of the literature. Arch Surg. 2008;143:305-308.

24. Yan BM, Pai RK, Van Dam J. Diagnosis of pancreatic gastrointestinal stromal tumor by EUS guided FNA. JOP. 2008;9:192-196.

25. Ganesh M, Kumar S, Krishnamoorthy R, Ang Y. Rare cause of pancreatic mass responding to imatinib treatment. Gastroenterology Today. 2008;18:50-51.

26. Paklina OV, Setdikova GR, Voskanyan SE. Gastrointestinal Stromal Tumor of a Pancreas: Case Report and literature review. Медицинскаявизуализация 2013 ;2:122.

27. Daum O, Klecka J, Ferda J, Treska V, Vanecek T, Sima R, Mukensnabl P, Michal M. Gastrointestinal stromal tumor of the pancreas: case report with documentation of KIT gene mutation. Virchows Arch.2005;446:470-472.

28. Krska Z, Pesková M, Povýsil C, Horejs J, Sedlácková E, Kudrnová Z. GIST of pancreas. Prague Med Rep. 2005;106:201208.

29. Pauser U, da Silva MT, Placke J, Klimstra DS, Klöppel G. Cellular hamartoma resembling gastrointestinal stromal tumor: 
a solid tumor of the pancreas expressing ckit (CD117) Mod Pathol.2005;18:12111216.

30. Neto MR, Machuca TN, Pinho RV, Yuasa LD, Bleggi-Torres LF. Gastrointestinal stromal tumor: report of two unusual cases. Virchows Arch. 2004;444:594-596.

31. Yamaura K, Kato K, Miyazawa M, Haba Y, Muramatsu A, Miyata K, Koide N. Stromal tumor of the pancreas with expression of c-kit protein: report of a case. J Gastroenterol Hepatol. 2004;19:467-470.

32. Faussone-Pellegrini MS, Thuneberg L. Guide to the identification of interstitial cells of Cajal. Microsc Res Tech. 1999;47:248-266.

33. Reith JD, Goldblum JR, Lyles RH, Weiss SW. Extra gastrointestinal (soft tissue) stromal tumors: an analysis of 48 cases with emphasis on histologic predictors of outcome. Mod Pathol. 2000;13:577-585.

34. Popescu LM, Hinescu ME, Ionescu N, Ciontea SM, Cretoiu D, Ardelean C. Interstitial cells of Cajal in pancreas. J Cell Mol Med. 2005;9:169-190.

35. Williams A, Gutzeit A, Germer M, Pless M. PET-Negative Gastrointestinal Stromal Tumors. Case Rep Oncol. 2013;6:508513.

36. Yamashita S, Sakamoto Y, Saiura A, Yamamoto J, Kosuge T, Aoki T, Sugawara Y, Hasegawa K, Kokudo N. Pancreassparing duodenectomy for gastrointestinal stromal tumor. Am J Surg. 2014;207:578583.

37. Beham AW, Scheefer IM, Schuler P, Cameron S, Ghadimi BM: Gastrointestinal stromal tumors. Int J Colorectal Dis. 2012, 27: 689-700. 10.1007/s00384-011-1353-y.

38. Beham A, Schaefer IM, Cameron S, von Hammerstein K, Fuzesi L, Ramadori G, Ghadimi MB: Duodenal GIST: a single center experience. Int $\mathbf{J}$ Colorectal Dis.
2013, 28: 581-590. 10.1007/s00384-0121432-8.

39. Buchs NC, Bucher P, Gervaz P, Ostermann S, Pugin F, Morel P: Segmental duodenectomy for gastrointestinal tumor stromal tumor of the duodenum. World J Gastroenterol. 2010, 16: 2788-2792. 10.3748/wjg.v16.i22.2788.

40. Miettinen M, Kopczynski J, Makhlouf HR, Sarlomo-Rikala M, Gyorffy H, Burke A, Sobin LH, Lasota J: Gastrointestinal stromal tumors, intramural leiomyomas, and leiomyosarcomas in the duodenum: a clinicopathologic, immunohistochemical, and molecular genetic study of 167 cases. Am J SurgPathol. 2003, 27: 625-631. 10.1097/00000478-200305000-00006.

41. Meng L, Fang SH, Jin M. An unusual case of pancreatic and gastric neoplasms. Eur Radio 2011;21:663-5.

42. Miettinen M, Lasota J: Gastrointestinal stromal tumors: pathology and prognosis at different sites. SeminDiagnPathol. 2006, 23: 70-83. 10.1053/j.semdp.2006.09.001.

43. Miettinen M, Monihan JM, SarlomoRikala M, Kovatich AJ, Carr NJ, Emory TS, Sobin LH: Gastrointestinal stromal tumors/smooth muscle tumors (GISTs) primary in the omentum and mesentery: clinicopathologic and immunoistochemical study of 26 cases. Am J SurgPathol. 1999, 23: 1109-1118. 10.1097/00000478199909000-00015.

44. Owen DA: Stomach. In: Mills SE, ed. His tology for pathologists, ed. 3. Philadelphia: Lippincott Williams \& Wilkins; 2007:589602.

45. Silva E, Teixeira A, David L, Carneiro F, Reis CA, Sobrinho Simoes J, Serpa J, Veerman E, Bolscher J, Sobrinho-Simoes M: Mucins as key molecules for the classification of intestinal metaplasia of the stomach. VirchowsArch 2002; 440: 311-317. 
46. Carachi R, Azmy A: Foregut duplications. PediatrSurgInt 2002; 18:371-374.

47. Ludviková M, Michal M, Datková D: Gast ric xanthelasma associated with diffuse signet ring carcinoma. A potential diagnostic problem. Histopathology 1994;25:581-582.

48. Espinosa I, Lee CH, Kim MK, Rouse BT, Subramanian S, Montgomery K, Varma S, Corless CL, Heinrich MC, Smith KS, Wan g Z, Rubin B, Nielsen TO, Seitz RS, Ross DT, West RB, Cleary ML, van de Rijn M: A novel monoclonal antibody against DOG1 is a sensitive and specific marker for gastrointestinal stromal tumors. Am J SurgPathol 2008; 32:210-218.

49. Miettinen M, Wang ZF, Lasota J: DOG1 antibody in the differential diagnosis of gastrointestinal stromal tumors: a study of 1840 cases. Am J Surg Pathol 2009; 33:1401-1408.

50. West RB, Corless CL, Chen X, Rubin BP, Subramanian S, Montgomery K, Zhu S, B all CA, Nielsen TO, Patel R, Goldblum J, Brown PO, Heinrich MC, van de Rijn M: The novel marker, DOG1, is expressed ubiquitously in gastrointestinal stromal tumors irrespective of KIT or PDGFRA mutation status. Am J Pathol 2004; 165:107-113.

51. Kaifi JT, Strelow A, Schurr PG, Reichelt U, Yekebas EF, Wachowiak R, Quaas A, S trate T, Schaefer H, Sauter G, Schachner M, Izbicki JR: L1 (CD171) is highly expressed in gastrointestinal stromal tumors. Mod Pathol 2006; 19:399-406.

52. Bertagnolli MM. Gastrointestinal stomal tumors. In: Zinner MJ, Ashley SW. eds. Maingots abdominal operations. $11^{\text {th }}$ edn. New York: McGraw-Hill Professional, 2007.

53. Cecka F, Jon B, Ferko A, et al. Long-term survival of a patient after resection of a gastrointestinal stromal tumor arising from the pancreas. Hepatobiliary pancreat Dis Int2011;10:330-2.

54. Yasuda A, Sawai H, Takahashi H, et al. The stem cell factor/c-kit receptor pathway enhances proliferation and invasion of pancreatic cancer cells. Mol cancer 2006; 5:46.

55. Agaimy A, Wunsh PH. Gastrointestinal stromal tumors: a regular origin in the muscularispropria, but an extremely diverse gross presentation. A review of 200 cases to critically re-evaluate the concept of so called extra-gastrointestinal stromal tumors. Langenbecks Arch Surg 2006; 391:322-9. 